La Revue

des Droits

de l'Homme

\section{La Revue des droits de l'homme}

Revue du Centre de recherches et d'études sur les droits fondamentaux

Actualités Droits-Libertés | 2011

Cour européenne des droits de l'homme

\title{
Renvoi en Grande Chambre
}

Cour européenne des droits de l'homme

\section{Nicolas Hervieu}

\section{CpenEdition}

\section{Journals}

Édition électronique

URL : http://journals.openedition.org/revdh/5789

DOI : $10.4000 /$ revdh.5789

ISSN : 2264-119X

Éditeur

Centre de recherches et d'études sur les droits fondamentaux

Référence électronique

Nicolas Hervieu, «Renvoi en Grande Chambre », La Revue des droits de l'homme [En ligne], Actualités Droits-Libertés, mis en ligne le 19 mars 2011, consulté le 20 avril 2019. URL : http://

journals.openedition.org/revdh/5789; DOI : 10.4000/revdh.5789

Ce document a été généré automatiquement le 20 avril 2019

Tous droits réservés 


\title{
Cour européenne des droits de l'homme
}

\section{Renvoi en Grande Chambre}

\author{
Cour européenne des droits de l'homme
}

\section{Nicolas Hervieu}

1 Le collège de cinq juges (Art. 43) a accepté le renvoi en Grande Chambre de la Cour européenne des droits de l'homme de deux affaires, pour chacune sur demande de l'État défendeur condamné par la formation de Chambre :

2 - L'affaire Konstantin Markin c. Russie (Cour EDH, 1e Sect. 7 octobre 2010, Req. n 30078/06 ADL du 8 octobre 2010) : Revirement de jurisprudence sur l'octroi d'un congé parental à un père et répartition sexuée des rôles dans l'éducation des enfants (constat de violation de l'article 14 combiné à l'article 8 - Discrimination dans la jouissance du droit au respect de la vie privée et familiale) ;

3 - L'affaire Kurić c. Slovénie (Cour EDH, 3e Sect. 13 juillet 2010, Req. nº 26828/06 - ADL du 27 juillet 2010) : Situation des personnes "effacés " et devenus apatrides lors du processus de dissolution de la Yougoslavie (constat de violation de l'article 8 - Droit au respect de la vie privée et familiale).

4 Les autres demandes de renvoi ont été rejetées. Ainsi, et notamment, sont désormais définitifs les arrêts rendus en formation de Chambre dans :

5 - L'affaire Y.P. et L.P. c. France (Cour EDH, 2e Sect. 2 septembre 2010, Req. n 32476/06 - ADL du 1er septembre 2010) : Risques de mauvais traitements en cas de renvoi par la France d'une famille d'opposants politiques vers la Biélorussie (constat de violation conditionnelle de l'article 3 : interdiction de la torture et des peines et traitements inhumains et dégradants) ;

6 - L'affaire Xiros c. Grèce (Cour EDH, 1e Sect. 9 septembre 2010, Req. n 1033/07 - ADL du 9 septembre 2010) : Qualité des soins dispensés à un détenu grièvement blessé - Constat de violation de l'article 3 : interdiction de la torture et des peines et traitements inhumains et dégradants).

7 Renvois acceptés et refusés en Grande Chambre de la Cour européenne des droits de l'homme - Communiqué de presse du Greffier du 15 mars 2011 


\section{AUTEUR}

NICOLAS HERVIEU

Nicolas Hervieu est un juriste français en droit public, spécialiste de la Cour européenne des droits de l'homme 